\title{
Research on the Application of Metaphor in Business English Translation
}

\author{
Cui Min
}

Yinchuan University of Energy, Ningxia, Yinchuan, 750105

Keywords: Metaphor, Business English Translation, Application Method

\begin{abstract}
There are a lot of metaphors used in business English. As a way of thinking and cognitive means, metaphor frequently appears in business English. On the basis of discussing the roles and classification of metaphors and the principles of metaphor translation in business English, the paper proposes to focus on the clarity and accuracy of information, to understand the context where metaphors are used, to maintain the metaphorical features as much as possible and to process the mapping in metaphor translation.
\end{abstract}

\section{Introduction}

Through the research in the last ten years, it is found that cognitive linguistics is not only a language rhetorical device, but also a way of thinking, mainly reflecting the essential characteristics of people's conceptual traditions, as well as people's thinking, action and understanding basis. Therefore, the process of metaphor is the process of thinking creation of the speaker or the author. It is to find a connection point and similarity between the two concepts, so as to express the unfamiliar or abstract image. Business English has a certain speciality, so it is also very distinctive when applying metaphor. It can be said that the quality of metaphor translation in business English directly determines whether business communication is smooth.

\section{The Roles of Metaphor in Business English}

Metaphors are often used in people's daily life. As business development is gradually cited by business terms, and some have been solidified into business terms in business English, metaphors in business communication are very common. For example, the word "cow" is the meaning of a cow. It is a kind of livestock in people's common sense, and metaphor is to find the relevance of new concepts and known concepts. The cows in the cognition are hard-working and can reproduce the descendants. On the basis of this connotation, Lenovo is transformed into a "cash cow, a huge source of money" when translating "cash cow". Metaphor has a great role in business English, but things have two sides, and there are negative effects besides positive effects. The following is an analysis of the roles of metaphor in business activities from both positive and negative aspects.

Metaphor is a way of knowing the world. There are new things happening in business communication. However, due to the limitations of people, time, place or lack of necessary experience, it is impossible to understand each new concept. The role is revealed. For example, when we talk about products, we will use "product life cycle". The meaning of "life cycle" in common sense is very clear. It refers to the life cycle of people. Here, the subject is replaced by "product", which makes it easy to make people understand that products and humans have a cycle of production, existence and extinction. In this way, people can get a good idea of this new concept.

Metaphor has a high degree of generalization. The use of a metaphor can save a lot of words and achieve better expression. Take the sentence "Now this is another share bubble" for example. "Share bubble" simply and vividly describes the current stock market situation as a bubble, which is vulnerable to false prosperity. If you don't use the word "bubble", you need a lot of other words to modify and describe the situation.

In business communication or business documents, the use of metaphorical rhetoric can make others feel the artistic level and cultural connotation of the other party or the author, and it is easy for people to think according to his wishes and perspectives, which is more conducive to the 
conduct of business activities. If you are discussing the price, in addition to giving a fair price, you need to let the other party understand the concessions made by your party and let the other party realize your sincerity. At this time, some people will use the phrase "mends these fences" in the sentence "Let us try to mend these fences of price." The metaphor "fences of price" needs the "repair" of both sides, which means that we are willing to make price concessions. I also hope that the other party will do the same. The use of metaphors here expresses my intentions subtly, without losing the sense of art.

\section{Classifications of Metaphor in Business English}

A noun form of metaphor takes advantage of a common feature between two things, enabling people to infer complex, strange, or other specialized terms in the field through familiar things. In this way, people's understanding of new things or new concepts will be more specific. Such as "Since a big part of every employee's compensation is tied to achieving the standard, the system has teeth." (From "Collins Cobuild English Grammar Series 7: Metaphor") means "Since each employee's compensation is in line with the standards that have been met. This system is very effective." "Teeth" is meant to be a tooth. The system has teeth, which means that the system is effective and powerful. In this way, the reader can feel the power of the system vividly, just like a tooth. There are also many noun metaphors. The most common ones are "pillar", "backbone", "bull", "bear", "overhead" and so on. A variety of noun metaphors enable people to better understand strange things, or naturally associate with the characteristics of new things.

In the metaphor of verb form, vehicle and tenor often appear at different times, but are reflected by metaphorical verbs. Metaphorical verbs are the expression of abstract, incomprehensible trends or behaviors using familiar verbs. Such as "The rest of the world is moving into cyberspace more slowly than the United States, and, in the developing world, the Internet has hardly peeled at all" (Zhou Yin, 2018, P.114), "Move into" and "penetrate" in this sentence subtly refract the actions of "moving" and "infiltration" to "the rest of the world" and "developing countries", so that the action of the image is added to the abstract concept in it. This sentence is therefore translated as "compared with the United States, the speed of other places into the electronic space is slower, and in developing countries, the penetration of the Internet is almost zero." A large number of verbs such as "grow", "hit", "engage", "mobilize", "run" have been cited in business English. The use of metaphorical verbs makes the expression vivid, and it is easy for people to better understand the operation, behavior, and situation of business.

Adjective metaphors are also widely used more in business English. The vehicle does not appear. The original adjectives that modify the vehicle are used to describe the modified tenor directly, so as to make people associate and perceive new or unfamiliar things or concepts. For example, when people say that the economic situation is not good, they will use adjectives such as "weak" and "dead-alive". "Weak" generally describes people or things that are not strong. "Dead-alive" also refers to people who are listless. Therefore, bad economy will be associated with lifeless man. In addition, the common adjective metaphors are "liquid", "depression", "frozen", "assigned", "dull" and "floating". Not only nouns, verbs and adjectives, but also adverbs and some synthetic words can be metaphorically applied to business English in metaphorical rhetoric. This also requires people to fully exert their imagination and creativity in business activities. Since the application of metaphors associates abstract and complicated business concepts with concrete and true-to-life image, it makes business English expressions simpler and more vivid, and adds color to business activities.

\section{Translation of Business English Metaphor}

Specific to business English, the metaphor has its own characteristics different from literary works: Economic terms are rigorous and thorough, and the writing is concise. The use of metaphor is to convey economic information vividly. Therefore, the translation should pay both attention to the clarity and accuracy of the information and artistry of different languages. The understanding of English needs to be related to context, and the understanding of context needs to be familiar with 
the professional knowledge in business operation. Only when familiar with the terms commonly used in business activities can we accurately locate and translate.

In general, metaphorical understanding can be divided into two basic steps: The first step is the identification of metaphors, that is, the discourse signals or signs that identify metaphors, the semantic or pragmatic signals of metaphors. The specific method can refer to the following procedures: Confirm the literal meaning of the discourse; Infer the applicability and authenticity of the literal meaning against the contextual assessment; Infer the non-literal meaning of the context and the principle of cooperation (Liu Zhenqian, Shi Xiaoying, 2002, P.18). For example, the sentence "The auditing methods, once the lame ducks of American accounting agencies, have been transformed thanks to the company s cooperation with Pricewaterhouse." means that the audit method was once the weakness of American accounting firms, and now it has changed significantly, thanks to the cooperation of the company with Pricewaterhouse Coopers. At first, the translator has a full understanding of the original domain in the translated language in order to recognize the metaphorical discourse signal. In this sentence, the translator should understand the lame ducks literally. "Lame" means "unable to walk because your leg is injured", so a lame duck is inconvenient to move. Depending on the context, there is obviously a semantic flaw in the literal sense. This is the specific cognitive process in which the translator recognizes metaphors.

The second step is the translator's inference of metaphorical meaning. The process of understanding metaphorical meaning is actually the process in which the translator transfers the main features of the tenor in the metaphor to the vehicle and thus re-understands the vehicle. In the metaphorical concept system, the meaning of metaphor depends fundamentally on the meaning and structural features of the original domain. Due to the empirical nature, metaphor is common in human's mind. Therefore, the mapping from the original domain, which is usually concrete, familiar and intuitive, to the target domain, which is usually abstract, unfamiliar and conceptual is the cognitive process of understanding a metaphor.

Metaphor translation is also a metaphor because it is also a mapping from one concept domain to another, but the concept domain now refers to different languages. This process also requires translators to look for the same or similar concept expressions in both languages. When the mapping from the original domain to the target domain of the translated language is similar to the mapping of the original domain to the target domain in the original language, the metaphor reconstruction faced by the translator is relatively simple. This situation is generally a literal translation. However, metaphors have different degrees of difference in the orientation of the projection of different national languages or the transformation of conceptual organization. Therefore, in most cases, the mapping between the original domain and the target domain of the translated language is quite different or even contradictory to the mapping of the original domain to the target domain in the original language. At this time, the translator needs to carefully recognize and adopt the free translation method to achieve accurate purpose.

\section{Conclusion}

In China's reform and opening up over the past 40 years, all undertakings have been developing rapidly. In particular, the ever-changing changes in the economic field are even more remarkable. At the same time, some new abstract concepts in the economic field are difficult to understand, the reproduction of metaphors in business English makes abstract and complex concepts concrete, simple, vivid, and visual, and at the same time easy to be understood by most people. Metaphor is not only a rhetorical method, but also a cognitive method and a thinking method. It exists in business English widely, so it has a strong application to metaphor research in business English. To balance the clarity and art of of information transmission in metaphor translation, the translator needs to study the metaphor in the context and strengthen the understanding of the cultural connotation of metaphor, and adopt different translation strategies flexibly. 


\section{References}

[1] Cui Na. The Metaphor in Business English and Its Translation Principles [J]. English on Campus, 2016(1).

[2] Deigan, A. Collins Cobuild Grammar Series 7: Metaphor [M]. Foreign Languages Press, 2001.

[3] Gao Bei. Characteristics and Translation Strategies of Business English under the Background of Globalization, English Square, 2018(8).

[4] Lakoff, G. \& Johnson, M. Metaphors We Live By [M]. University of Chicago Press, 1980.

[5] Liu Zhenqian, Shi Xiaoying. The Cultural Cognitive Essence of Metaphor and Foreign Language Teaching [J]. Foreign Languages and Their Teaching, 2002(2).

[6] Xu Jun, Zi Zhengquan. A Corpus-Based Study on the E-C Translation of Business Report MetaphorS. Business Languages and Communication, 2018(1).

[7] Zhou Yin. Metaphorical Translation in Business Negotiation English from a Cognitive Perspectiv. Overseas English. 2018(2). 